\title{
Results From Shanghai's (China) 2016 Report Card on Physical Activity for Children and Youth
}

\author{
Yang Liu, Yan Tang, Zhen-Bo Cao, Pei-Jie Chen, Jia-Lin Zhang, Zheng Zhu, \\ Jie Zhuang, Yang Yang, and Yue-Ying Hu
}

\begin{abstract}
Background: Internationally comparable evidence is important to advocate for young people's physical activity. The aim of this article is to present the inaugural Shanghai (China) Report Card on Physical Activity for Children and Youth. Methods: Since no national data are available, the working group developed the survey questionnaire and carried out the school surveys for students $(\mathrm{n}=71,404)$, parents $(\mathrm{n}=70,346)$, and school administrators and teachers $(\mathrm{n}=1398)$. The grades of 9 report card indicators were assigned in accordance with the survey results against a defined benchmark: $A$ is $81 \%$ to $100 \% ; B$ is $61 \%$ to $80 \%$; $C$ is $41 \%$ to $60 \%, D$ is $21 \%$ to $40 \% ; F$ is $0 \%$ to $20 \%$. Results: The 9 indicators were graded as follows: Overall Physical Activity Levels $(F)$, Organized Sport Participation $(F)$, Active Play $(D-)$, Active Transportation $(C$-), Sedentary Behavior $(F)$, Family and Peers $(B)$, School $(B+)$, Community and the Built Environment $(D+)$, and Government $(D)$. Conclusions: Levels of physical activity and sedentary behavior were low and below the respective recommended guidelines. Interventions and policies at the community level should be encouraged to promote physical activity and reduce sedentary behavior. Future national surveys should be encouraged to strengthen Shanghai's Report Card on Physical Activity for Children and Youth.
\end{abstract}

Keywords: exercise, sedentary behavior, policy, advocacy, health promotion

It has been well documented that physical activity (PA) can benefit young people's healthy growth and development, maintenance of energy balance, psychological well-being, social interaction, and academic and cognitive performance..$^{1-5}$ One hour of moderate-to-vigorous intensity physical activity (MVPA) is recommended everyday for 5- to 17-year-olds by the World Health Organization (WHO) $)^{6}$ and several countries. ${ }^{5,7}$ Similar to many other countries, ${ }^{8}$ China suffers the burden of declining PA levels and increasing sedentary behavior among school-aged children, the likely result of broad social changes. ${ }^{9-11}$ Shanghai, located on the east coast of China, is one of the biggest and most populous cities in both China and the world, with a population of more than 24 million. The proportion of children and youth from Shanghai (the most developed city in China) who meet the recommendation of 1 hour of MVPA everyday is very low. ${ }^{12}$

To better understand young people's PA behaviors and the related environmental factors, and to influence policy makers, the first step of promoting young people's PA is to monitor its current status. Therefore, an international comparable research protocol and knowledge translation model is needed. The Active Healthy Kids Canada (AHKC) Report Card has been successful in releasing information on

Liu, Tang, Cao, Chen, Zhu, and Zhuang are with the Shanghai Research Center for Physical Fitness and Health of Children and Adolescents, Shanghai University of Sport, Shanghai, China. Liu and Tang are also with, and Zhang and $\mathrm{Hu}$ are with, the School of Physical Education and Sport Training, Shanghai University of Sport, Shanghai, China. Cao, Chen, Zhu, and Zhuang are also with the School of Kinesiology, Shanghai University of Sport, Shanghai, China. Yang is with the Shanghai Municipal Center for Students' Physical Fitness and Health Surveillance, Shanghai, China. Liu (docliuyang@hotmail.com) and Chen (chenpeijie@sus.edu.cn) are corresponding authors. the PA of young Canadians and has influenced policies, programs, and interventions. ${ }^{13}$ To date, there is a lack of national or regional survey data available on young people's PA and sedentary behavior which are comparable across countries. In September 2014, the Shanghai Municipal Education Commission established the Shanghai Research Center for Physical Fitness and Health of Children and Adolescents (SH-RCPFHCA) at the Shanghai University of Sport (SUS), which initiated the inaugural report card program in China. The first goal of the SH-RCPFHCA was to conduct the 2016 Shanghai (China) Report Card. Later on, the SH-RCPFHCA will engage in implementing the report card at a national level, coordinated by Ministry of Education of People's Republic of China.

The purpose of this paper is to present the procedures and the results of the inaugural Shanghai (China) Report Card on Physical Activity for Children and Youth. In addition, the grade for each indicator is briefly described. The data herein were derived from a survey carried out from October 2014 to February 2015, in which more than 78,000 children aged 6 to 18 years, representing 5\% of the population of children and youth in Shanghai, as well as their parents, school administrators, and teachers, participated.

\section{Methods}

The working group for the development of the 2016 Shanghai (China) Report Card included 6 researchers with expertise in PA and young people's health and 2 doctoral students from the Shanghai University of Sport. In addition, 2 international experts, Professor Mark Tremblay from the Children's Hospital of Eastern Ontario Research Institute, Canada, and Professor Weimo Zhu from the University of Illinois at Urbana-Champaign, USA, were invited to participate in the development of the report card.

The 2016 Shanghai (China) Report Card followed the procedures developed by Active Healthy Kids Canada ${ }^{13}$ and endorsed 
by the Active Healthy Kids Global Alliance (AHKGA). Before the study, the working group conducted a search of the English and Chinese literature in September 2014. Due to the fact that very few studies covered the 9 indicators used in the report card, the working group decided to design their own survey questionnaire and implement a survey. The Delphi method was used to select the items in the survey through a 3-round procedure with over 20 national experts in PA research. Consistent with the Global Matrix of report card grades, ${ }^{14}$ all 9 indicators were included in the survey questionnaire, assessed by related questions (Table 1).

A large-scale school survey was conducted from October 2014 to February 2015 using a multistage stratified, random cluster sampling method. A total of 711 primary, secondary, and upper secondary schools were selected from all 17 districts of the Shanghai metropolitan area. In total, 78,516 students (aged 6 to 18 years) and their parents were invited to participate in the survey. In response, 71,404 students (51\% boys) and 70,346 parents completed the self-report questionnaire (response rate $=90.9 \%$ and $89.6 \%$ ). In addition, 1398 school administrators and teachers from these 711 schools also completed the school survey questionnaire. Based on the survey results, grades were assigned for the 9 indicators by determining the proportion of children and youth that achieved an identified benchmark, where: $A$, referred to Shanghai succeeding with $81 \%$ to $100 \%$ (a large majority of children and youth); $B$, with $61 \%$ to $80 \%$ (well over half of children and youth); $C$, with $41 \%$ to $60 \%$ (about half of children and youth); $D$, with $21 \%$ to $40 \%$ (less than half, but some, children and youth); $F$, with $0 \%$ to $20 \%$ (very few children and youth); and Incomplete (INC) if insufficient data were available with which to assign a grade. For each indicator, the upper $5 \%$ of grade range is marked with ' + ' and the lower $5 \%$ of each grade range is marked with '-'. The school survey was conducted by researchers with expertise in the related area and organized by Shanghai Municipal Education Commission, with grades assigned from the first-hand survey results. Furthermore, a chi-square test was used to compare the difference in percentages between groups, with the criterion of significance set at $P<.05$. All analyses were conducted in SPSS v20.0.

\section{Results and Discussion}

The 2016 Shanghai (China) Report Card is the inaugural annual assessment of PA in mainland China. The grades are summarized in Table 2 and the cover page is presented in Figure 1.

\section{Overall Physical Activity Levels: $\boldsymbol{F}$}

Overall Physical Activity Levels is the key indicator in the Report Card. Students were asked to report on how many of the past 7 days they were physically active for at least 60 minutes. The grade of $F$ was determined as the percentage of young people in Shanghai who met the PA guideline of at least 60 minutes of MVPA daily ${ }^{6}$ was only $19.7 \%$. Boys $(21.6 \%)$ were more active than girls $(17.6 \%)$ $(P<.01)$. The rates of meeting the PA guideline decreased notably with age from primary school (boys: $27.9 \%$, girls: $27.5 \%$ ), to secondary school (boys: $19.3 \%$, girls: $12.4 \%$ ), and finally to upper secondary (boys: $9.7 \%$, girls: $3.5 \%)(P<.001)$. These results are similar to those reported in a global study showing that more than $80 \%$ of children do not meet recommended levels of PA, that boys are more active than girls, and that PA decreases with age. ${ }^{8}$ The grade of $F$ reflects the very low overall PA levels of children and youth in Shanghai, China, which might be caused by the increasing of sedentary behavior and the lifestyle of physical inactivity.

\section{Organized Sport Participation: $\boldsymbol{F}$}

Organized Sport Participation is an important way for children and youth to participate in PA. Students were asked whether they had participated in organized sport and/or PA programs over the past 12 months. The grade of $F$ for Organized Sport Participation was determined as the percentage of young people participating in organized sports/programs was only $14.9 \%$. For girls, the percentage is only $12 \%$, which is lower than for boys (17\%). Compared with other countries, for example in Australia where more than half of children and young people participate in organized sport, ${ }^{15}$ the grade of $F$ reflects a very poor situation of organized sport participation

Table 1 Indicators and Survey Instruments of the 2016 Shanghai (China) Report Card on Physical Activity for Children and Youth

\begin{tabular}{ll}
\hline Indicator & Survey instruments \\
\hline Overall Physical Activity Levels & $\begin{array}{l}\text { Daily moderate-to-vigorous physical activity (MVPA) at least } 60 \text { minutes in } \\
\text { past 7 days }\end{array}$ \\
Organized Sport Participation & $\begin{array}{l}\text { Participation of organized sport and/or physical activity (PA) programs over the } \\
\text { past 12 months }\end{array}$ \\
Active Play & $\begin{array}{l}\text { Participation in unstructured/unorganized PA at least 4 times during past week } \\
\text { Going school by walk or bicycle }\end{array}$ \\
Active Transportation & $\begin{array}{l}\text { Watching TV/film, playing computer/video games, surfing the internet and } \\
\text { doing homework at least 2 hours per day on weekdays and weekends }\end{array}$ \\
Family and Peers & $\begin{array}{l}\text { Response 'very often' at least 2 items for parents support for PA of their chil- } \\
\text { dren }\end{array}$ \\
School & $\begin{array}{l}\text { 1) students' satisfaction with physical education (PE) and exercise-related } \\
\text { opportunities in school; 2) the amount of accredited PE teachers with state } \\
\text { teacher qualification; 3) PA after school; 4) PE classes; 5) facilities and equip- } \\
\text { ment for sport and exercise in school; and 6) the school administrator's concern } \\
\text { about PA, exercise and PE of students. } \\
\text { Facilities and equipment, sports organizations and community sports activities }\end{array}$ \\
Community and the Built Environment & Parents' awareness around the national physical activity policies \\
\hline Government Strategies and Investments &
\end{tabular}


Table 2 Grades According to Physical Activity Indicator in the 2016 Shanghai (China) Report Card on Physical Activity for Children and Youth

\begin{tabular}{lc}
\hline Indicator & Grades \\
\hline Overall Physical Activity Levels & $F$ \\
Organized Sport Participation & $F$ \\
Active Play & $D-$ \\
Active Transportation & $C-$ \\
Sedentary Behavior & $F$ \\
Family and Peers & $B$ \\
School & $B+$ \\
Community and the Built Environment & $D+$ \\
Government Strategies and Investments & $D$ \\
\hline
\end{tabular}

Note. The grade for each indicator is based on the percentage of children and youth meeting a defined benchmark: $A$ is $81 \%$ to $100 \% ; B$ is $61 \%$ to $80 \%$; $C$ is $41 \%$ to $60 \%, D$ is $21 \%$ to $40 \% ; F$ is $0 \%$ to $20 \%$. For each indicator, the upper $5 \%$ of grade range is marked with '+' and the lower $5 \%$ of each grade range is marked with ' - '.

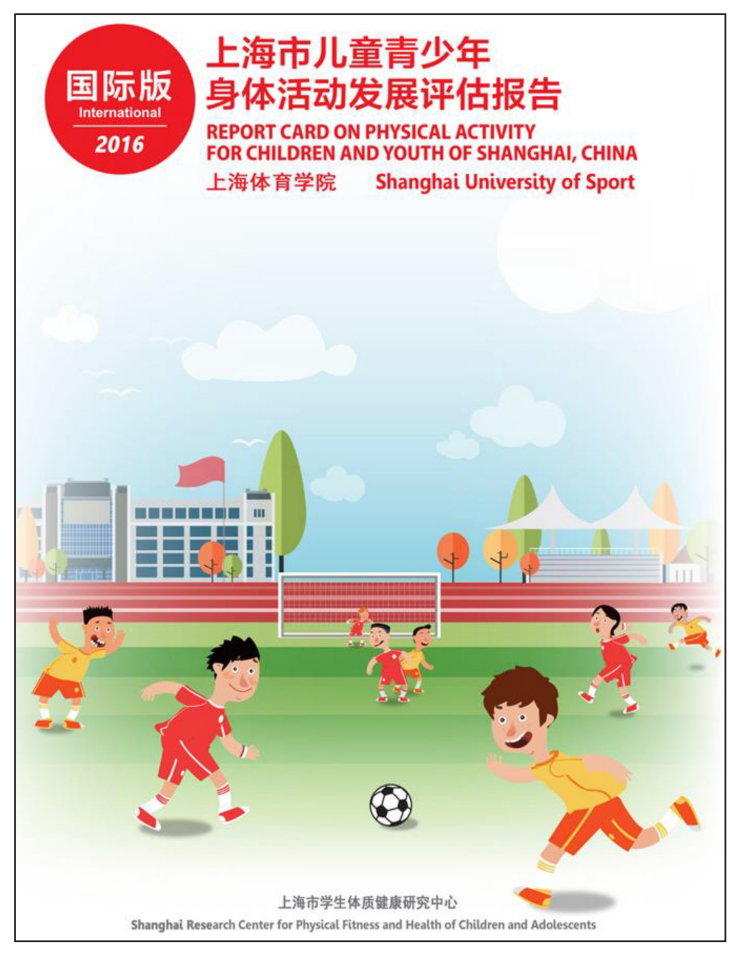

Figure 1 - Front cover of the 2016 Shanghai (China) Physical Activity Report Card for Children and Youth.

in Shanghai, China. One possible reason might be that there are few sport clubs or sport organizations for Chinese young people compared with most western countries.

\section{Active Play: D-}

Active Play is defined as the percentage of children and youth who engage in unstructured/unorganized active play for several hours a day. Besides organized sport participation, active play is another important path for students to be physically active. Students were asked how many times during the past week they engaged in unorganized active and outdoor play (at least 60 minutes per occasion). Overall, $22.3 \%$ of young people reported that they participated in unorganized active and outdoor play at least 4 times during past week, hence the grade of $D$ - for Active Play. Although this grade is better than that for Organized Sport Participation, active play levels among children and youth in Shanghai, China are still very low. The reasons underlying the low levels of active play might be the heavy homework load and academic pressure on Chinese students. There is also a lack of space for children and youth to take part in PA outside school.

\section{Active Transportation: C-}

Regarding Active Transportation, students were asked about their transportation mode of going to school every day. Active transportation was defined as the percentage of young people who walk or cycle to school, with a grade of $C$ - assigned based on survey results. Specifically, $32.7 \%$ and $8.4 \%$ of children and youth travel to school by foot and bike, respectively. China used to be seen as the kingdom of the bicycle. However, with the Chinese economy booming and the automotive industry developing, more and more people own their own car, especially in big cities like Shanghai. The current study revealed that $37.7 \%$ of students travel to school in the family car, which is lower than in US, ${ }^{16}$ but higher than in Finland. ${ }^{17}$

\section{Sedentary Behavior: $\boldsymbol{F}$}

For Sedentary Behavior, students were asked to report how many hours they spent watching TV/film, playing computer/video games, surfing the internet, and doing homework per day, both on weekdays and weekend days. The grade of $F$ for Sedentary Behavior was determined by the percentage of young people who spend 2 hours or more everyday in these activities. The survey revealed that $75.2 \%$ of young people reported at least 2 hours of sedentary behavior per weekday and $88.6 \%$ per weekend day $(P<0.01)$. Girls are more sedentary than boys on both weekdays (boys $74.9 \%$, girls $75.5 \%$ ) and on the weekend (boys $84.8 \%$, girls $88.8 \%)(P<0.01)$. The proportion of at least 2 hours of sedentary behavior increases with age. The grade of $F$ reflects the very high level of sedentary behavior of children and youth in Shanghai, China. Increasing screen-based time, in particular the use of the computer and internet, and doing homework are the main reasons that contribute to the high levels of sedentary behavior.

\section{Family and Peers: B}

Support from family and peers is an important protective asset and critical for young people's participation in PA. ${ }^{18}$ Family support was assessed in the survey by asking parents about their support of their kids' PA, including encouragement, accompanying, financial support, and modeling, etc. The responses were 'very often,' 'often,' 'sometimes,' 'not often,' and 'not at all.' Family support was determined by the percentage of those who chose the 'very often' response for at least 2 items. We found $73.9 \%$ of parents reported that they support their children and therefore a grade of $B$ was assigned. The results demonstrated that most parents in Shanghai support their children's PA and exercise, which might be due to the fact that most parents know the health benefits of PA and they want their kids be healthy. It should be noted that peer support was not assessed in the survey. Hence, the grade of $B$ only represents family support, not peer support. 


\section{School: $B+$}

Students spend most of their time in school, therefore the school environment is vitally important for their PA. In the present study, the school environment contains 6 items asked of students and school administrators/teachers: 1) students' satisfaction with physical education and exercise-related opportunities in school; 2) the amount of accredited physical education teachers with state teacher qualification; 3) PA after school; 4) physical education classes; 5) facilities and equipment for sport and exercise in school; and 6) the school administrator's concern about PA, exercise, and physical education of students. The grade of $B+$ was assigned based on the average percentage $(80.1 \%)$ across the aforementioned school indicators. In general, school administrators and teachers were concerned with their students' PA and they provided enough facilities and equipment to facilitate opportunities for PA. A total of $86.1 \%$ of students were satisfied with their current physical education classes and exercise opportunities in school. The grade of $B+$ reflects that schools in Shanghai, China provide a good environment and opportunities for PA.

\section{Community and the Built Environment: $D+$}

Facilities and equipment, sports organizations, and community sports activities were 3 aspects measured in the survey for this indicator. The grade of $D+$ was assigned based on the average percentage $(35.9 \%)$ across the aforementioned indicators. While about one-quarter to one-half of the children reported there are facilities $(55.3 \%)$ and programs $(28.4 \%)$ in their community, only $16.7 \%$ reported that sports organizations/clubs were located in their community. This poor result indicates that sports organizations and activities should be promoted, as well as improvements in the quantity and quality of community facilities and equipment.

\section{Government: D}

The Chinese Government has prioritized the PA and health of children and youth. ${ }^{19}$ In 2007, the State Council of the People's Republic of China introduced a national policy regarding the promotion of PA and enhancement of physical fitness of children and youth, known as the No.7 Central Document. ${ }^{19}$ Since then, the State Council and the Ministry of Education of the People's Republic of China has released several policies and funds to support the PA of children and youth. If only whether there are government strategies and investments, listed as core indicators and benchmarks, was evaluated for this indicator, this grade for the whole main land of P. R. China should always be an $A$ because there are national policies, strategies, and funding, etc. However, it does not necessarily, or cannot reflect the fact of the effects of these government strategies and investments. As defined by the AHKGA, one of the benchmarks for this indicator is "demonstrated progress through the key stages of public policy making (ie, policy agenda, policy formation, policy implementation, policy evaluation, and decisions about the future)." Thus, the Government indicator was assessed by gauging the public awareness around the national PA policies, and despite these policies being updated nearly every decade, only $26.7 \%$ of parents reported being aware of such polices, hence the low $D$ grade.

\section{Strengths and Limitations}

This is the inaugural Report Card on Physical Activity of Children and Youth in mainland China. One prominent strength of this study is that the working group developed questionnaires for students, parents, school administrators, and teachers, respectively, and conducted the school survey to get first-hand data to assess all 9 core report card indicators. The large sample size and representative samples from the Shanghai metropolitan area provide a high quality of evidence for grade assignment. Apart from these strengths, it should be pointed out that the 2016 Shanghai Report Card only represents Shanghai and cannot be considered as the report card of China due to the large economic and geographic differences between Shanghai and the rest of China. In addition, while self-report measures may overestimate PA and underestimate sedentary behavior, self-report measures demonstrate reasonable reliability in a Chinese context. ${ }^{20}$ Finally, items assessing peer support were not included in the survey questionnaire.

\section{Conclusion}

To conclude, the current study demonstrated that more than $80 \%$ of young people in Shanghai, China are physical inactive and sedentary. The support structures, such as the family environment, schools, and government, are well developed in China, although community factors are lagging and need to be improved. In future, surveys should be encouraged across other provinces or at the national level to develop a representative national Report Card on Physical Activity for Children and Youth of China.

\section{Acknowledgments}

This work was supported by grants from Science and Technology Commission of Shanghai Municipality (14490503700), (15490503000), Education Commission of Shanghai Municipality (HJTY-2014-A08), the Key Area Research Project from General Administration of Sport of China (2014B070), Shuguang Program by Shanghai Education Development Foundation and Shanghai Municipal Education Commission (14SG46), and Shanghai Key Laboratory of Human Performance (Shanghai University of sport, 11DZ2261100). The authors appreciate Professor Mark Tremblay (Children's Hospital of Eastern Ontario Research Institute, Canada), Professor Weimo Zhu (University of Illinois at Urbana-Champaign, USA), and Dr Grant Tomkinson (University of North Dakota, USA; University of South Australia, Australia) for supporting this work. Furthermore, the authors would like thank all students, parents, school administrators, and teachers who participated in the school surveys.

\section{References}

1. Biddle SJH, Gorely T, Stensel DJ. Health-enhancing physical activity and sedentary behavior in children and adolescents. J Sports Sci. 2004;22:679-701. PubMed doi:10.1080/02640410410001712412

2. Martínez-Gómez D, Ruiz JR, Gómez-Martínez S, et al, the AVENA Study Group. Active commuting to school and cognitive performance in adolescents: the AVENA study. Arch Pediatr Adolesc Med. 2011;165:300-305. PubMed doi:10.1001/archpediatrics.2010.244

3. McMurray RG, Harrell JS, Creighton D, Wang Z, Bangdiwala SI. Influence of physical activity on change in weight status as children become adolescents. Int J Pediatr Obes. 2008;3:69-77. PubMed doi:10.1080/17477160701789794

4. Strong WB, Malina RM, Blimkie CR, et al. Evidence based physical activity for school-age youth. J Pediatr. 2005;146:732-737. PubMed doi:10.1016/j.jpeds.2005.01.055

5. U.K. Department of Health. At Least Five a Week: Evidence on the Impact of Physical Activity and its Relationship to Health. London: Department of Health; 2004. 
6. World Health Organization. Global Recommendations on Physical Activity for Health. Geneva: World Health Organization; 2010.

7. Canadian Society for Exercise Physiology. Canadian Physical Activity Guidelines for Youth 12-17 Years. Canada; 2011.

8. Hallal PC, Andersen LB, Bull FC, Guthold R, Haskell W, Ekelund U. Global physical activity levels: surveillance progress, pitfalls, and prospects. Lancet. 2012;380:247-257. PubMed doi:10.1016/S01406736(12)60646-1

9. Du S, Lu B, Zhai F, Popkin B. A new stage of the nutrition transition in China. Public Health Nutr. 2002;5(1A):169-174. PubMed

10. Tudor-Locke C, Ainsworth BE, Adair LS, Du S, Popkin BM. Physical activity and inactivity in Chinese school-aged youth: the China Health and Nutrition Survey. Int J Obes Relat Metab Disord. 2003;27:10931099. PubMed doi:10.1038/sj.ijo.0802377

11. Duan J, Hu H, Wang G, Arao T. Study on current levels of physical activity and sedentary behavior among middle school students in Beijing, China. PLoS One. 2015;10:1371-1383. PubMed doi:10.1371/ journal.pone.0133544

12. Wang L, Jing Q. Association between family structure and physical activity of Chinese adolescents. BioMed Res Int. 2016;1:1-7. PubMed

13. Colley RC, Brownrigg M, Tremblay MS. A model of knowledge translation in health: the Active Healthy Kids Canada Report Card on Physical Activity for Children and Youth. Health Promot Pract. 2012;13:320-330. PubMed doi:10.1177/1524839911432929

14. Tremblay MS, Gray CE, Akinroye K, et al. Physical activity of children: a global matrix of grades comparing 15 countries. J Phys
Act Health. 2014;11(Supp 1):S113-S125. PubMed doi:10.1123/ jpah.2014-0177

15. Australian Bureau of Statistics (ABS). Australian Health Survey: Physical Activity, 2011-2012. Catalogue No. 4364.0. Canberra: Aus Bureau Statistics; 2013.

16. Dentro KN, Beals K, Crouter SE, et al. Results from the United States' 2014 report card on physical activity for children and youth. $J$ Phys Act Health. 2014;11(Supp 1):S105-S112. PubMed doi:10.1123/ jpah.2014-0184

17. Turpeinen S, Lakanen L, Hakonen H, Havas E, Tammelin T. On the Way to School. School Commutes and the Promotion of Active Com muting Amongst School-aged Children. Research Reports on Sport and Health 271, Jyvaskyla: LIKES-foundation for sport and health sciences. Finnish report, abstract in English; 2013.

18. Wang X, Hui Z, Terry PD, et al. Correlates of insufficient physical activity among junior high school students: a cross-sectional study in Xi'an, China. Int J Environ Res Public Health. 2016;13:397-406. PubMed doi:10.3390/ijerph13040397

19. The State Council of the P. R. China. Promoting physical activity and enhancing physical fitness of children and adolescents. http://www.moe.edu.cn/publicfiles/business/htmlfiles/moe/ moe_1581/201006/88663.html. Accessed June 12, 2016.

20. Liu Y, Wang M, Tynjälä J, et al. Test-retest reliability of selected items of Health Behaviour in School-aged Children (HBSC) survey questionnaire in Beijing, China. BMC Med Res Methodol. 2010;10:73-82. PubMed doi:10.1186/1471-2288-10-73 